\title{
ATIVISMO JUDICIAL NA EDUCAÇÃO INFANTIL
}

\author{
Leonardo Pereira Martins ${ }^{1}$ \\ Fernanda Rodrigues Pires de Moraes $^{2}$
}

\section{Resumo:}

$\mathrm{O}$ artigo trata do ativismo judicial voltado à eficácia das políticas públicas destinadas à viabilização da educação infantil sob enfoque de teorias do Pós-constitucionalismo e da Análise Econômica do Direito. Invoca-se, nesse aspecto, o conceito de racionalidade limitada, a limitação informacional dos operadores de direito, e o princípio da eficiência na implementação de recursos escassos visando à obtenção de soluções de maior impacto econômico e social. Constatou-se a judicialização da educação infantil parcialmente integrada com as demais políticas públicas de viabilização do direito de acesso a creches e pré-escolas, com potencial viabilidade de atendimento a demandas do mercado.

Palavras-chave: Ativismo Judicial; Análise Econômica do Direito; Educação infantil; Políticas Públicas.

\section{JUDICIAL ACTIVISM IN CHILDHOOD EDUCATION}

\begin{abstract}
:
The article deals with judicial activism aimed at the effectiveness of public policies aimed at making child education viable under the theories of Post-constitutionalism and the Economic Analysis of Law. In this respect, the concept of limited rationality, the informational limitation of legal operators, and the principle of efficiency in the implementation of scarce resources aiming at obtaining solutions of greater economic and social impact are invoked.
\end{abstract}

Keywords: Judicial Activism; Economic Analysis of Law; Child education; Public policy.

\section{INTRODUÇÃO}

$\mathrm{O}$ ativismo judicial e seus reflexos na eficácia das políticas públicas ${ }^{3}$ de viabilização da educação infantil é o tema a ser examinado neste artigo, com enfoques teórico-dogmático e empírico. Abordam-se os diversos dispositivos constitucionais, da legislação, da teoria

\footnotetext{
${ }^{1}$ Especialista e mestre em Direito. Egresso do Programa de Pós-Graduação em Direito Agrário da Universidade Federal de Goiás (UFGO), é servidor de carreira do Poder Judiciário goiano e integra o corpo de assessoria do Tribunal de Justiça do Estado de Goiás. leonardopmartins@ hotmail.com

${ }^{2}$ Especialista, mestra e doutoranda em Direito. Aluna do Programa de Doutorado em Direito do Centro Universitário de Brasília (UniCEUB), é servidora de carreira do Poder Judiciário e goiano e integra o corpo de assessoria do Tribunal de Justiça do Estado de Goiás. frpmoraes1@ gmail.com

${ }^{3}$ Neste artigo, considerou-se política pública "o programa de ação governamental que resulta de um processo ou conjunto de processos juridicamente regulados [...] visando coordenar os meios à disposição do Estado e as atividades privadas, para a realização de objetivos socialmente relevantes e politicamente determinados." (BUCCI, 2006, p.39).
} 
constitucional contemporânea e da Análise Econômica do Direito, confrontando este substrato a dados empíricos. Serão examinadas as prescrições constitucionais, em suas interpretações vigentes, e a evolução da teoria constitucional nas últimas décadas. Como contraponto, ferramenta de equilíbrio e ponderação contaremos com o apoio das discussões da Análise Econômica do Direito.

O tema foi escolhido diante da inquietação em face da inefetividade dos direitos fundamentais expressos na Magna Carta, em razão da falta de atuação do Poder Executivo, dando àquele documento jurídico superior um caráter de mero enunciador de dispositivos inócuos, desconexos da realidade e das necessidades sociais. Essa ausência de atuação, no entanto, não tem impedido a jurisprudência, com amparo nos princípios constitucionais e normas gerais de emprestar eficácia aos comandos constitucionais.

Por outro lado, não são raras as críticas ao ativismo judicial, destacando-se a alegada violação do princípio republicano, à independência e separação dos poderes, à democracia, o risco de politização judiciária e a ausência de parâmetros para seus limites. Particularmente neste último aspecto, destaca-se o temor de se permitir que a hipertrofia de um Poder (o Judiciário) imponha a sujeição dos demais e a decorrente viabilidade de se dirigir os efeitos econômicos das decisões judiciais (nesse modelo, definidoras da atuação estatal), interferindo na prestação de outros serviços públicos. Essa nova mecânica de funcionamento dos poderes, segundo os críticos do ativismo judicial, viabilizaria ao Judiciário beneficiar ou prejudicar setores detrimento de outros, sob a legítima, embora dita equivocada, preferência dos fins sociais às limitações econômicas do Estado. As preocupações com a ampliação do ativismo judicial são dignas de extrema atenção.

Com efeito, assumindo a premissa de que o ativismo judicial não é tencionado mas praticado, também é preocupação central deste estudo estabelecer com fundamento nas prescrições constitucionais, quais seriam seus limites na efetivação do direito à educação infantil e os possíveis reflexos.

A Análise Econômica do Direito e as críticas ao Pós-constitucionalismo são vetores teóricos desse estudo. A partir da primeira, enfoca-se o conceito de racionalidade limitada, a limitação informacional dos operadores de direito, e o princípio da eficiência, o qual se relaciona com a implementação de recursos escassos visando à obtenção de soluções de maior amplitude econômica e social. Com aporte no Pós-constitucionalismo pretende-se explicitar os valores envoltos na judicialização da educação infantil e seus vetores contrapostos, ponto 
de partida para a compreensão da ponderação de valores implementada concretamente nas decisões judiciais temáticas e para o exame das possíveis consequências desses provimentos, tanto as endógenas à economia estatal como a exógenas a ela, mais interessantes ao mercado.

A interpretação concedida ao direito à educação infantil e o decorrente dever estatal de supri-la atendem a um só tempo diretrizes constitucionais e legais e à necessidade do mercado. No vigente contexto de arrocho orçamentário para custeio da máquina estatal, que opera a favor da vinculação pró-mercado de cada vez maiores parcelas orçamentárias na forma de juros de dívida púbica, a imposição ao Estado de arcar com os ônus financeiros decorrentes pode comprometer a eficácia social e econômica de outras políticas públicas educacionais que concorrem pelo mesmo orçamento. Demonstra-se, contudo, não se tratar de uma realidade jurídico-social desalinhada do viés capitalista.

Assumir as consequências dessas demandas judiciais como custo ou investimento social e econômico é ponto fundamental para o atendimento dos destinatários do direito à educação infantil e para legitimar o dispêndio financeiro dos entes estatais obrigados às decorrentes contraprestações. O contexto evoca a possibilidade de aplicação de soluções cooperativas e judiciais. A Análise Econômica do Direito, como informado, serve de instrumento para a busca da concretização e efetividade deste direito, viabilizando compreender os interesses dos sujeitos ativos e passivos das obrigações em exame.

Um último recorte se erige à abordagem da questão proposta. Trata-se de delimitar metodologicamente em termos político-geográficos e temporais a coleta de dados empíricos sobre o tema. Quanto à primeira delimitação, relaciona-se flagrantemente ao lugar de fala dos autores, enquanto integrantes da equipe de assessoria jurídica do Tribunal de Justiça goiano.

Em sua dimensão empírica, o estudo identifica precedentes qualificados (assim entendidos, aqueles cuja obediência impõe-se a todos os juízos vinculados ao tribunal que os tenha produzido e a produção de súmulas temáticas. A segunda delimitação é temporal: a coleta de dados empíricos dirigiu-se documentos publicados até abril de 2020, disponibilizados para consulta pública, via da rede mundial de computadores nos sítios virtuais das cortes de justiça estaduais. Desse, modo, espera-se que a leitura se revele adequada e útil à compreensão de aspectos da judicialização das políticas públicas na área da educação, tema que, embora não inédito à literatura jurídica, tem facetas inexploradas, algumas das quais adiante abordadas. 


\section{ATIVISMO JUDICIAL NO BRASIL}

Visto sob um aspecto operacional, chama-se ativismo judicial o fenômeno pelo qual, no Brasil, tem se alargado o campo de atuação do Poder Judiciário no controle dos atos discricionários do Poder Executivo. Esse alargamento chegou ao ponto em que a ação judicante deixou de ser meramente repressiva e exercitada concretamente, à semelhança do controle difuso de constitucionalidade, para converter-se, em razão do volume de situações que a clamam, num balizador da atuação da Administração na definição das formas de execução de políticas públicas e até no redesenho e redimensionamento destas políticas.

Essa dimensão operacional não é aleatória. Antes, a faceta palpável e sensorial do fenômeno decorre de uma condição teórica e dogmática somente viável a partir da incorporação de aspirações e de elementos do pós-constitucionalismo, especialmente no que toca à eficácia material dos direitos fundamentais. A asserção ecoa Cittadino (2002), para quem a ampliação do controle do Poder Judiciário, favoreceu-se da promulgação da Constituição Federal de 1988. Diz mais: "que, ao incorporar direitos e princípios fundamentais, configurar um Estado Democrático de Direito e estabelecer princípios e fundamentos do Estado, viabiliza uma ação judicial que recorre a procedimentos interpretativos de legitimação de aspirações sociais" (CITTADINO, 2002, p. 135).

O estudo do ativismo judicial na efetivação da educação infantil, é caudatário desse aporte conceitual. Importa-lhe o exame dos dispositivos constitucionais correlatos, da Lei de Diretrizes e Bases da Educação Nacional e também exige proceder a uma análise evolutiva crítica da teoria constitucional, a qual se propõe desenvolver com aportes de pósconstitucionalismo.

\subsection{O PROTAGONISMO ESTATAL NA EFETIVAÇÃO DOS DIREITOS FUNDAMENTAIS DE SEGUNDA GERAÇÃO}

Direitos Fundamentais antecedem a ideia de constitucionalismo, o qual "[...] tão somente consagrou a necessidade de insculpir um rol mínimo de direitos humanos em um documento escrito, derivado diretamente da soberana vontade popular." (MORAES, 2011, p. 2). O que faz a Constituição é positivar Direitos Fundamentais no âmbito dos Estados. As Magnas Cartas como hodiernamente se conhecem são um reflexo da positivação dos Direitos Fundamentais que acompanhou o estabelecimento da rigidez e da supremacia constitucionais predominantes no Estado de Direito. 
Satisfaziam-se os direitos fundamentais, inicialmente, por meio de uma mera conduta passiva do Estado. Entretanto, ao largo do tempo e do desenvolvimento da sociedade, o comportamento negativo do Estado patenteou insuficiência no atendimento das novas exigências que surgiam e das demandas por novos direitos. Reclamaram-se atitudes positivas. De acordo com Paulo Bonavides (2002), o lema da Revolução Francesa (liberdade, igualdade e fraternidade) "anunciou” a ordem histórica da gradativa institucionalização dos Direitos Fundamentais, que culminou, originalmente, em três gerações (ou dimensões, como prefere o lente), em modo sucessivo: direitos da liberdade, da igualdade e da fraternidade.

Interessa a este estudo os direitos da segunda geração (ou dimensão) são os sociais, culturais e econômicos. Tais direitos surgiram com o Estado social, são entendidos como direitos da coletividade e advieram do princípio da igualdade. Para a sua concretização exigem prestações por parte do Estado (atitudes positivas). Neste aspecto, a Constituição brasileira, no seu art. $5^{\circ}, \S 1^{\circ}$, assegurou a auto aplicabilidade das normas definidoras dos direitos e garantias fundamentais.

Em que pese as pesquisas mais abalizadas referirem a cinco gerações ou dimensões de direitos os de segunda geração ainda suscitam debates no Brasil centrados na eficácia e efetividade que inspiram. Essas discussões não escapam do reconhecimento da insuficiência e ineficiência dos instrumentos executório-materiais a fazer-lhes frente. Para Noberto Bobbio (1992, p. 5-19), os direitos de segunda geração operam-se "por meio" do Estado, ou seja, é através deste que os indivíduos poderão obter a sua satisfação. $\mathrm{Na} \mathrm{CF} / 88$, os citados direitos ocupam o capítulo designado "Dos Diretos Sociais", em que constam vários Direitos Fundamentais, dentre eles os direitos a educação, a saúde, ao trabalho, a moradia, ao lazer e a segurança. (CF, art. $6^{\circ}$, caput).

Nesta perspectiva, os direitos fundamentais receberam um novo conceito, e passaram a ser objetivados. Bonavides (2002) sustenta que o Estado passou a ter a obrigação de criar pressupostos fáticos para a efetiva realização dos direitos, imprescindíveis ao pleno exercício da liberdade, sobre os quais o indivíduo é destituído de poder. Dada a constatação da mera formalidade dos direitos de primeira geração e de que seus preceitos de fato não se estendiam a todos, verificou-se a necessidade de atribuir ao Estado a função de efetivar direitos por meio de prestações (tutela positiva).

Aqui o intercâmbio entre os direitos fundamentais e o direito administrativo revela-se profícuo, resultando os primeiros em fontes de normatividade para a institucionalização de 
políticas públicas. No mesmo passo, as tendências de efetivação dos direitos fundamentais situam a proposta deste artigo em linha com o aludido intercâmbio e permitem advogar um direito administrativo constitucional regente das políticas públicas. Numa interligação necessária entre as definições de direitos fundamentais, políticas públicas, e ativismo judicial, pode-se dizer que "as políticas públicas surgem como instrumento de atuação do Estado na efetivação dos direitos fundamentais, indo além desse objetivo e resultando na diminuição das desigualdades e na inserção social da população como um todo" (SLONIAK, 2015).

Diante das dificuldades de se implementar as políticas públicas, em razão da atuação deficiente dos Poderes Legislativo e Executivo, o Judiciário é comumente chamado a socorrer os indivíduos, tornando-se em guardião do cumprimento das demandas sociais. Na tarefa de resolver os conflitos sociais, ao Judiciário se apresentam duas posturas distintas e alternativas, a de "garantista" e a de "ativista", sendo aquela mais conservadora e limitada à doutrina clássica da separação dos poderes e, a última, mais avançada, criativa e consciente de que em suas decisões haverá o dever de cumprimento dos comandos constitucionais, ainda que não disponha da autorização legislativa explícita que sustente sua atuação. Neste sentido, Barroso:

A ideia de ativismo judicial está associada a uma participação mais ampla e intensa do Judiciário na concretização dos valores e fins constitucionais, com maior interferência no espaço de atuação dos outros dois Poderes. A postura ativista se manifesta por meio de diferentes condutas, que incluem: (i) a aplicação direta da Constituição a situações não expressamente contempladas em seu texto e independentemente de manifestação do legislador ordinário; (ii) a declaração de inconstitucionalidade de atos normativos emanados do legislador, com base em critérios menos rígidos que os de patente e ostensiva violação da Constituição; (iii) a imposição de condutas ou de abstenções ao Poder Público, notadamente em matéria de políticas públicas. (BARROSO, 2008).

A discussão a respeito do referido dualismo, juiz "garantista" ou "ativista", entrou na agenda do meio acadêmico brasileiro nas últimas décadas, e fez surgir defesas fervoras a respeito de uma e outra postura. Entende-se necessário um exame temático que extravase o citado dualismo. Assumir essa dualidade nega a riqueza das fontes sociais, políticas e econômicas na criação dos direitos. Não se supõe um juiz que, diante de um caso concreto, antes de conhecer de suas vicissitudes, de antemão se coloque como garantista ou ativista. Essa adjetivação, se é viável, realiza-se pelo resultado alcançado com a decisão e não por 
outro motivo. Além disso, a atuação judicial só se viabiliza no vácuo da ação dos Poderes Legislativo e Executivo, resultando em acertamentos jurídicos a ser procedidos para manutenção da inteireza do sistema no tocante à concretude dos direitos e à consequência das decisões, mormente quando geradoras de despesas. No contexto, até mesmo a contabilidade pública se impacta, impondo novos agires.

O Direito constitucional contemporâneo cada vez mais reforça o papel social das constituições democráticas republicanas, documento composto por princípios e regras dotados de caráter normativo, fonte de inspiração e condicionador de todo o ordenamento jurídico infraconstitucional. Já agora, realiza-se sob inspiração em elementos originalmente ausentes, os valores e os princípios ${ }^{4}$, e não mais supõe atribuir supremacia ao texto constitucional na ótica meramente formal que pautou a leitura das constituições no entre guerras. A partir dessa ressignificação valorativa e principiológica pretende a ativação dos enunciados constitucionais definidores de direitos, atribuindo eficácia aos direitos fundamentais. Para muitos, tem-se aí a essência do pós-constitucionalismo ${ }^{5}$.

Sempre bom lembrar que a própria Constituição Federal já prevê em seu artigo $5^{\circ}, \S$ $1^{\circ}$, que as normas definidoras dos direitos e garantias fundamentais têm aplicação imediata. Segundo se pode inferir dessa diretriz constitucional e da interpretação teleológica de outros dispositivos, tanto os direitos sociais quanto os direitos políticos e de nacionalidade, dentre outros, hão de ser lidos como dotados de plena eficácia, por exigência do Estado Social de Direito, sendo possível por isso o controle judicial da omissão administrativa.

\subsection{DOGMÁTICA DA JUDICIALIZAÇÃO DA EDUCAÇÃO INFANTIL}

Sobre o direito fundamental à educação infantil, enuncia a Constituição Federal:

Art. $6^{\circ}$ São direitos sociais a educação, a saúde, a alimentação, o trabalho, a moradia, o transporte, o lazer, a segurança, a previdência social, a proteção à maternidade e à infância, a assistência aos desamparados, na forma desta Constituição.

Art. 205. A educação, direito de todos e dever do Estado e da família,

\footnotetext{
4 Com Alexy (1993), distinguimos princípios e valores jurídicos, situando os primeiros no campo deontológico e os segundos no campo da axiologia. "Lo que en el modelo de los valores es prima facie lo mejor es, en el modelo de los principios, prima facie debido; y lo que en el modelo de los valores es definitivamente lo mejor es, en el modelo de los principios, definitivamente debido. Así pues, los principios y los valores se diferencian sólo en virtud de su carácter deontológico y axiológico respectivamente" (ALEXY, 1993, p. 147).

5 "O neoconstitucionalismo surge na revisão do constitucionalismo efetuada pós-segunda guerra mundial e ao defender a força normativa da constituição pressupõe uma nova teoria do direito fundada numa concepção principialista das normas constitucionais” (DEMARCHI e VANDRESEN, 2015, p. 46.).
} 
será promovida e incentivada com a colaboração da sociedade, visando ao pleno desenvolvimento da pessoa, seu preparo para o exercício da cidadania e sua qualificação para o trabalho.

Art. 206. O ensino será ministrado com base nos seguintes princípios: I - igualdade de condições para o acesso e permanência na escola; [...]

Art. 208. O dever do Estado com a educação será efetivado mediante a garantia de:

$[\ldots]$

IV - educação infantil, em creche e pré-escola, às crianças até 5 (cinco) anos de idade (BRASIL, 1988);

Voltando ao exame específico do direito social à educação, a legislação infraconstitucional também assegura à criança, notadamente até os 6 (seis) anos de idade, o direito a obter do Poder Público educação gratuita e de qualidade, como preconiza o Estatuto da Criança e do Adolescente (Lei federal no 8.069/90). Veja-se, que o acréscimo (legal, e não constitucional) na idade dos destinatários da medida, sinaliza ao intérprete o alargamento do direito fundamental formalmente inserido na diretriz das políticas públicas temáticas:

Art. 54. É dever do Estado assegurar à criança e ao adolescente:

$[\ldots]$

IV - atendimento em creche e pré-escola às crianças de zero a seis anos de idade;

$[\ldots]$

Art. 88. São diretrizes da política de atendimento:

I - municipalização do atendimento;

Art. 208. Regem-se pelas disposições desta Lei as ações de responsabilidade por ofensa aos direitos assegurados à criança e ao adolescente, referentes ao não oferecimento ou oferta irregular:

$[\ldots]$

III - de atendimento em creche e pré-escola às crianças de zero a cinco anos de idade; (BRASIL, ECA, 1990)

Quanto à obrigação imposta aos municípios de oferecer creches e pré-escolas aos infantes na referida faixa etária, em reforço ao disposto no Estatuto da Criança e do Adolescente, estabelece a Lei de Diretrizes Básicas da Educação Nacional (Lei 9.394/96, art. 11) que:

“Os Municípios incumbir-se-ão de: [...]

$\mathrm{V}$ - oferecer a educação infantil em creches e pré-escolas, e, com prioridade, o ensino fundamental, permitida a atuação em outros 
níveis de ensino somente quando estiverem atendidas plenamente as necessidades de sua área de competência e com recursos acima dos percentuais mínimos vinculados pela Constituição Federal à manutenção e desenvolvimento do ensino. (BRASIL, LDB, 1996)

Da norma transcrita ressai límpida a obrigação imposta aos municípios de oferecer vagas às suas crianças em creches e pré-escolas. E a jurisprudência da corte estadual goiana, limite geográfico metodologicamente imposto a esta pesquisa, ainda entende que a sujeição municipal compreende a matrícula em unidade de ensino próxima da residência do infante. É o que se infere do teor do verbete n. 39 da Súmula do Tribunal de Justiça do Estado de Goiás:

Tanto o mandado de segurança como a ação ordinária são instrumentos hábeis ao exercício do direito fundamental da criança ao atendimento em creche ou pré-escola situada nas proximidades da sua moradia, mantida ou custeada pelos municípios, admitindo-se bloqueio de valores em caso de descumprimento da obrigação (artigo 208, IV da CF e 54, IV do ECA). (GOIÁS, 2016).

A aplainar a questão, o Supremo Tribunal Federal, em 2016, ao apreciar o Agravo de Instrumento n. ${ }^{\circ} 761908$, converteu-o no Recurso Extraordinário n. ${ }^{\circ} 1008166$, por reconhecer a questão dotada de repercussão geral, enunciada nos termos do tema 548, a perquirir sobre o Dever estatal de assegurar o atendimento em creche e pré-escola às crianças de zero a 5 (cinco) anos de idade.

Não, há, contudo, até a presente data, solução de mérito no Recurso Extraordinário n. ${ }^{\circ}$ 1008166, a vincular a interpretação constitucional cabível, o que importa volumes elevados de lides individuais a repercutir na mesma questão de fundo.

\section{A ANÁLISE ECONÔMICA DO DIREITO}

Análise Econômica do Direito, nos Estados Unidos, onde encontrou útero fértil, Law and Economics, é um movimento desenvolvido desde a década de 1970 de aderência crescente no meio acadêmico-jurídico, que associa conhecimentos e abordagens da economia e do direito, em perspectiva interdisciplinar. Sem distinguir tendências e escolas, Pacheco (1994, p. 181) resume-o como movimento contemporâneo, cuja característica comum seria a aplicação da teoria microeconômica neoclássica do bem-estar para analisar e reformular tanto instituições particulares como o sistema jurídico em seu conjunto. 
O desenvolvimento da Análise Econômica do Direito - AED deu-se no contexto conceitual do realismo jurídico norte-americano ${ }^{6}$, defensor de que os estudiosos da lei deveriam ocupar-se de examinar como ela funciona na prática, fazendo uso das ciências sociais, dentre elas a economia (ROEMER, 2000, p. 10). Tanto os economistas como os profissionais do direito acreditam nos modelos de conduta. Com a AED, houve a introdução de uma teoria mais abstrata de que as normas jurídicas são incentivos para a ação, e que as respostas dependem e variam em função dos tipos de incentivos envolvidos (ROEMER, 2000, p. 20). Tenciona a AED, a partir de técnicas analíticas próprias, viabilizar ao jurista avaliar que normas devem reger diferentes áreas.

Trata-se da ampliação da análise do Direito, com foco na eficiência prática máxima, por meio da inserção da teoria econômica e seus métodos, que são aplicados para examinar a lei (formação, estrutura, influência, etc.) e as instituições jurídicas (ROEMER, 2000, p. 6). A AED não se limita, portanto, às questões de mercado, leva em consideração a interdependência entre Direito e Economia, pois como os agentes econômicos, as pessoas reagem a incentivos fornecidos pelo ambiente em que vivem, que podem ser fornecidos pelo ordenamento jurídico. E as instituições que desempenham este papel são as regras jurídicas, os tribunais, dentre outras.

Para a análise do ativismo do Poder Judiciário e os seus potenciais efeitos na implementação de políticas públicas na área da educação infantil, a Análise Econômica do Direito dispõe do conceito de racionalidade limitada e do princípio da eficiência. Evoca-se, em relação à primeira, a limitação informacional dos operadores de direito e, o segundo relaciona-se com a implementação de recursos escassos visando à obtenção de soluções de maior eficiência econômica e social.

\subsection{RACIONALIDADE LIMITADA}

A racionalidade humana permite à pessoa analisar, planejar e executar suas atividades e desejos, pondo-os em prática. Para isso, o indivíduo deve ter em mente o que o separa dos bens e serviços preferidos. Os obstáculos são vários, por isso, são considerados

\footnotetext{
6 Alvarez (1996, p. 49) distingue mas divisa elementos comuns à Análise Econômica do Direito e à Escola Crítica do Direito Segundo. Segundo ele, “AED e o CLS podem ser vistos como continuadores da tradição realista americana em sua crítica ao formalismo e na construção do conhecimento jurídico. Com efeito, ambos os movimentos ressuscitam a ideia realista do direito como ciência baseada na metodologia e contribuições das ciências sociais" (ALVAREZ, 1996, p. 49).
} 
pelo homem (FEREJOHN e PASQUINO, 2001). Por outro lado, quem decide, sempre desejará aumentar o que foi alcançado (benefício marginal), o que leva a um obstáculo/custo maior (custo marginal). E, sendo o benefício marginal superior ao custo marginal, o indivíduo continuará fazendo modificações para aumentar os seus ganhos (COOTER, 2010, p. 45-46).

A maximização dos resultados, portanto, considera não apenas os benefícios iniciais diante dos custos iniciais, como os custos marginas. Os atos racionais estão ligados ao aumento do benefício marginal com custo marginal menor ou a manutenção dos benefícios iniciais com a redução de seus custos.

A Teoria da Escolha Racional defende a ponderação, isto é, a análise detalhada das vantagens e dos seus custos na tomada de decisão pelo indivíduo, o que é essencial quando da eleição pelo poder público de uma política pública específica, e para se entender os efeitos nefastos de um ativismo judicial ilimitado, e que não leva em consideração as consequências econômicas de suas decisões.

A limitação da racionalidade decorre da limitação da informação acessível aos agentes, além da incapacidade de processamento pelos seres humanos de toda a informação disponível sobre determinado assunto, verificável no momento em que os agentes pretendem agir. A melhor conduta, contudo, nem sempre se verifica, em razão de incertezas a respeito de determinada transação, das informações incompletas acerca do objeto negociado, e da complexidade de informações que envolvem o negócio.

Quando se analisa uma decisão judicial, a racionalidade limitada pressupõe as limitações de conhecimento dos juízes sobre as implicações econômicas de suas decisões, já que há limitações de informação, e incapacidade geral de seu processamento pelo ser humano. O julgador, na busca pela maior aplicabilidade e justiça da decisão, deve avaliar seus custos face à eficiência na alocação dos recursos objeto do litígio. Tal ponderação, relaciona-se ao consequencialismo que deve reger a solução de certos casos, especialmente quando atingem terceiros. Assim, os magistrados promovem uma análise subjetiva acerca da pretensão a eles apresentada, por envolver em geral situações de emergência quanto a direitos negligenciados.

\subsection{PRINCÍPIO DA EFICIÊNCIA NOS AMBIENTES JURÍDICO E ECONÔMICO}

Os recursos de produção, os ingredientes básicos para a criação de bens e serviços, são limitados, porém, as necessidades humanas estão sempre se renovando (VASCONCELLOS; GARCIA, 2000. p. 2). Neste contexto, a Economia atua como 
gerenciadora, tentando evitar o desperdício dos fatores produtivos face às vontades humanas, atingindo o equilíbrio.

A eficiência está ligada ao método da economia. A maximização das riquezas realiza as necessidades humanas e impõe criar a mesma quantidade de produção com o mais baixo custo. Outra concepção de eficiência, é a de Pareto ou alocativa, que considera não só a elevação do potencial do produto, pela diminuição dos custos produtivos, ou pelo aumento da fabricação com a mesma quantidade de insumos, mas também, pelo grau de satisfação das pessoas envolvidas. Assim, na impossibilidade de realocar produtos de modo a beneficiar uma parte, sem prejudicar a outra, haverá uma situação de Pareto eficiente. (VARIAN, 2003. p. $15)$.

Diante disso, a Economia contribui com o Direito, pois explica o comportamento humano (maximizador da eficiência), auxiliando a pensar e criar meios e formas de tornar as políticas públicas e os atos jurídicos mais eficientes. A justiça pode se beneficiar da discussão dos custos e benefícios, embora a eficiência não se iguale ao acesso aos direitos fundamentais, mormente à educação.

A questão da escassez de recursos públicos se coloca de maneira especial no acesso ao ensino. Com efeito, quando o Estado determina a aplicação em área específica, significa que reduziria o montante em outra, o que traria como consequência a desorganização da Administração Pública (AMARAL, 2001, p. 136). Sob uma ótica puramente econômica, segundo Pareto (1996), só haveria eficiência ${ }^{7}$ quando seria impossível aumentar a utilidade de uma pessoa sem reduzir a utilidade de outra, isto é, haveria uma alocação ótima de recursos. $\mathrm{O}$ aspecto econômico do conceito faz com que se considere que se estará numa condição de eficiência na medida em que à melhora da condição de um indivíduo ou família corresponda uma piora na situação de um outro indivíduo, ou família, ou classe.

Desse modo, observa-se que o princípio da eficiência, sob a ótica de Pareto, permite analisar se a alocação subjetiva de recursos para a concessão de matrícula ao litigante corresponde à medida economicamente eficiente e se esse meio de efetivação de direitos fundamentais é o mais apropriado para se chegar a um quadro de eficiência. $\mathrm{O}$ exame da

7 A Lei da Eficiência de Pareto é uma proposição devida ao engenheiro e economista franco-italiano Vilfredo Frederico Damaso Pareto, publicada em 1897, em seu Manual de Economia Política. Segundo essa proposição, a melhor condição de eficiência passou a ser conhecida como o ótimo de Pareto. 
eficiência sob essa escora teórica é sempre referencial e importa aferir a melhora da situação de um em função da piora da de outro (PARETO, 1996).

O conceito de Pareto é criticado por manter o status quo e desvalorizar a necessidade de modificação de situações consolidadas em proveito de um melhor resultado coletivo ou social. Sua utilidade no ambiente da eleição de escolhas trágicas, como as que se operam na judicialização de políticas públicas reside, justamente na inviabilidade de, a partir de Pareto, estabelecerem-se comparações interpessoais de bem-estar (PARETO, 1996).

Justamente porque o maior bem de uns poucos beneficiados pelo ativismo judicial importa algum mal à massa de destinatários dos recursos desalocados das políticas públicas pela decisão judicial é que se invoca esta construção teórica ao modo de redarguir o ativismo.

\section{INTERSECÇÕES ENTRE ATIVISMO JUDICIAL E POLÍTICAS PÚBLICAS}

Por meio da doutrina constitucional contemporânea e de uma interpretação que confira unidade à Constituição Federal e à "vontade" do Poder Legislativo na sua tarefa de legislador ordinário, de regulamentador da Magna Carta e produtor de emendas constitucionais é que se busca a legitimidade democrática do juiz ativista. O labor proposto, contudo, não deixa de admitir um outro lado dessa legitimação. Um lado que além de interessar ao direito, interessa aos que, no conjunto das forças ou, como disse Lassale (1933), no âmago dos fatores reais de poder, emoldurados na Constituição, revela que a busca pela maior eficácia dos direitos fundamentais é facilitada quando o específico direito fundamental sob tutela interessar não apenas ao indivíduo/sujeito de direito/cidadão que o busca, mas aos fatores do poder econômico incorporados à Constituição real (em oposição a formal), ainda referenciando em Lassale (1933).

A efetivação do direito à educação infantil interessa a seu destinatário imediato - a criança - mas interessa aos pais, às mães, a seus empregadores (todos estes interessados mediato-imediatos) e ao mercado (interessado mediato) que, ante a efetivação desse direito, conta com os pais da criança como sujeitos da divisão social do trabalho em moldes capitalistas, seja como mão de obra ativa ou como reserva de desvalor da primeira, atingida pelo excedente de oferta.

\subsection{ATIVISMO JUDICIAL E POLÍTICAS PÚBLICAS DE ENSINO INFANTIL EM NÚMEROS CENSITÁRIOS}


O apontamento autoriza evocação e reflexão quanto a dados divulgados pelo Ministério da Educação do Brasil. Segundo o Censo da Educação Básica/2019 (Brasil, 2020), enquanto o número de matrículas na educação infantil cresceu 12,6\% entre 2015 e 2019; no ensino fundamental em geral, no mesmo período, o número de matrículas caiu 3,6\% (3,5\% nos anos iniciais e 3,7\% nos anos finais; e o número total de matrículas do ensino médio reduziu mais ainda: $7,6 \%$.

Ainda que, a partir do dado bruto não se possa inferir o efeito da judicialização da educação infantil nos números de matrículas em creches e pré-escolas, admitindo que os vetores da orientação jurisprudencial não discrepem no exame de pedidos de matrícula para a educação infantil em relação às demais fases da educação formal, todas compreendidas no mesmo direito fundamental à educação, vislumbra-se que o ativismo judicial na educação infantil tem alinhamento com os resultados das políticas públicas definidas pelo legislativo e operadas pelo Executivo. Na fase da tenra infância em que as crianças demandam maiores cuidados, quando os pais e, especialmente, as mães são desalocadas do mercado de trabalho para mais esta demanda doméstica (aqui não se valida a prática, apenas se lhe constata), o Estado age realizando, como em nenhum outro momento da vida escolar, as políticas públicas educacionais.

\subsection{A JUDICIALIZAÇÃO DA EDUCAÇÃO INFANTIL NOS TRIBUNAIS}

Em estudo recente, Taporosky e Silveira (2019), pesquisadoras da área da Educação, procuraram quantificar a judicialização coletiva de lides tendentes a viabilizar o direito à educação infantil. O corte temporal da coleta de dados proposto na referida pesquisa foi circunscrito entre 2005 e 2016. 
ATIVISMO JUDICIAL NA EDUCAÇÃO INFANTIL

\begin{tabular}{|c|c|c|}
\hline \multicolumn{3}{|c|}{$\begin{array}{l}\text { Tabola } 1 \text { Strmulas dos Tribumais de Justica do Bravil sobre o denver estatal de } \\
\text { dispensapho de ensino infantil }\end{array}$} \\
\hline Tribunal & Sumula & Teor \\
\hline NORTE & 0 & \\
\hline TJ AC & $\mathrm{x}$ & $\mathrm{x}$ \\
\hline TJ AP & $\mathrm{x}$ & $\mathrm{x}$ \\
\hline TJAM & $\mathrm{x}$ & $\mathrm{x}$ \\
\hline TJ PA & $\mathrm{x}$ & $\mathrm{x}$ \\
\hline TJ ROO & $\mathrm{x}$ & $\mathrm{x}$ \\
\hline TJ RR & $\mathrm{x}$ & $\mathrm{x}$ \\
\hline TJ To & $\mathrm{x}$ & $\mathrm{x}$ \\
\hline NORDESTE & 1 & \\
\hline TJ AL & $\mathrm{x}$ & $\mathrm{x}$ \\
\hline TJ BA & $\mathrm{x}$ & $\mathrm{x}$ \\
\hline TJ CE & $\mathrm{x}$ & $\mathrm{x}$ \\
\hline TJMA & $\mathrm{x}$ & $\mathrm{x}$ \\
\hline TJ PB & $\mathrm{x}$ & $\mathrm{x}$ \\
\hline TJ PE & $\mathrm{x}$ & $\mathrm{x}$ \\
\hline TJ PI & $\mathrm{x}$ & $\mathrm{x}$ \\
\hline TJ RN & $\underbrace{\text { Summula }}_{32}$ & Conterdo ostrambo ao objeto desto artigo \\
\hline TJ SE & $\mathrm{x}$ & $\mathrm{x}$ \\
\hline CENTRO-OESTE & 1 & \\
\hline TJ GO & ${ }_{39}^{\text {Stumula }}$ & 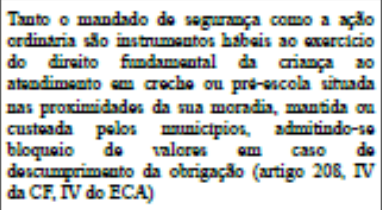 \\
\hline TJMT & $\mathrm{x}$ & $\mathrm{x}$ \\
\hline TJMS & $\mathrm{x}$ & $\mathrm{x}$ \\
\hline SUDESTF & 3 & \\
\hline TJES & $\mathrm{x}$ & $\mathrm{x}$ \\
\hline TJMG & $\mathrm{x}$ & $\mathrm{x}$ \\
\hline \multirow[b]{3}{*}{ TJ SP } & $\int_{63}^{\text {Sumula }}$ & 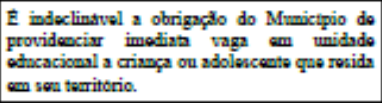 \\
\hline & Sưnula & 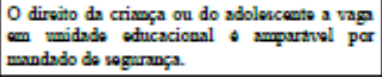 \\
\hline & $\int_{65}^{\text {Summula }}$ & 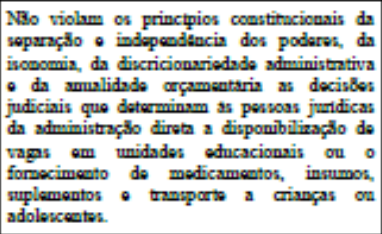 \\
\hline TJ RJ & $\mathrm{x}$ & $\mathrm{x}$ \\
\hline REGLÅO SUL & 1 & \\
\hline TJ PR & Strmula & Conteedo ostrambo ao objeto desto artigo \\
\hline TJ RS & $\mathrm{x}$ & $\mathrm{x}$ \\
\hline TJ SC & $\mathrm{x}$ & $\mathrm{x}$ \\
\hline \multicolumn{3}{|c|}{ 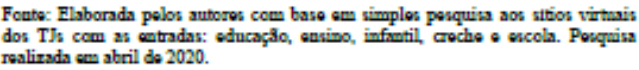 } \\
\hline
\end{tabular}

\begin{tabular}{|c|c|c|c|}
\hline \multicolumn{4}{|c|}{ 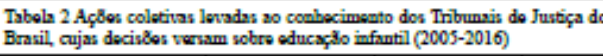 } \\
\hline Tribusal & Açlo civil peblica & $\begin{array}{l}\text { Mandado do } \\
\text { Seguramça }\end{array}$ & Outras \\
\hline NORTE & 12 & 0 & 1 \\
\hline TJAC & 3 & 0 & 0 \\
\hline TJAP & 1 & 0 & 0 \\
\hline TJAM & 1 & 0 & 0 \\
\hline TJ PA & 1 & 0 & 0 \\
\hline TJ RO & 4 & 0 & 0 \\
\hline TJRR & 0 & 0 & 0 \\
\hline TJ To & 2 & 0 & 1 \\
\hline NORDESTF & 21 & 0 & 0 \\
\hline TJ AL & 1 & 0 & 0 \\
\hline TJ BA & 1 & 0 & 0 \\
\hline $\mathrm{TJCE}$ & 0 & 0 & 0 \\
\hline TJMA & 1 & 0 & 0 \\
\hline TJ PB & 1 & 0 & 0 \\
\hline TJ PE & 0 & 0 & 0 \\
\hline TJ PI & 0 & 0 & 0 \\
\hline TJ RN & 1 & 0 & 0 \\
\hline TJ SE & 16 & 0 & 0 \\
\hline CENTRO-OESTE & 24 & 1 & 1 \\
\hline TJ GO & 4 & 1 & 0 \\
\hline TJMT & 13 & 0 & 0 \\
\hline TJMS & 7 & 0 & 1 \\
\hline SUDESTE & 129 & 5 & 5 \\
\hline TJ ES & 2 & 0 & 2 \\
\hline TJMG & 64 & 1 & 0 \\
\hline TJ SP & 58 & 4 & 3 \\
\hline TJ RJ & 5 & 0 & 0 \\
\hline REGLÁO SLL & 88 & 2 & 0 \\
\hline TJ PR & 21 & 1 & 0 \\
\hline TJRS & 25 & 0 & 0 \\
\hline TJ SC & 42 & 1 & 0 \\
\hline \multicolumn{4}{|c|}{ Fonte: Tuporouky o Silveira, 2019.} \\
\hline
\end{tabular}

O resultado das investigações junto aos órgãos de segundo grau das justiças estaduais do país, eleitos em função da competência dos municípios para a educação infantil já alhures justificada, foi expresso na Tabela 2, mantido o título dado pelas pesquisadoras na fonte consultada. Prosseguindo na investigação quantitativa da judicialização em lides coletivas, 
organizamos graficamente os dados encontrados por Taporosky e Silveira (2019) e os comparamos ao quantitativo de verbetes de súmulas temáticas dos tribunais estaduais. Os resultados revelam números igualmente tímidos, conforme apresentados na Tabela 1.

O exame dos números das lides coletivas (Tabela 2), cotejado ao quantitativo diminuto de súmulas temáticas das cortes estaduais (Tabela 1), acrescido, por fim da pendência de julgamento pelo Supremo Tribunal Federal do no Recurso Extraordinário n. ${ }^{\circ}$ 1.008.166, sugere um quadro em que o ativismo judicial na educação infantil também pode ser justificado pela baixa preocupação dos juízos com o enfrentamento do tema em termos de decisões vinculantes. Repetem-se decisões individuais em quantidades consideráveis, não aferidas nesse estudo em função do tempo exíguo na confecção do texto, mas pouco se investe em soluções qualificadas e dotadas de verticalidade.

\section{GESTÃO DOS EFEITOS DO ATIVISMO JUDICIAL EM SEDE DE ENSINO INFANTIL}

Quanto aos limites do ativismo judicial na efetivação dos direitos fundamentais, foca-se aqui na invocação à "reserva do possível" (SARLET, 2003) como contraponto da prestação estatal. Essa defesa, contudo, só é legítima nas situações em que a realização de uma prestação pelo Estado não é possível por comprovada e efetiva ausência de recursos, o que difere daquelas em que a falta destes decorre de sua alocação em desconformidade com a Constituição.

Da mesma maneira, um adequado planejamento da demanda por educação infantil, geográfica e economicamente circunscrito, aliado a boas técnicas de gestão pública e a ferramentas eficientes de acompanhamento gerencial revelam-se eficazes no enfrentamento da judicialização da educação infantil. Embora não se negue tratar de uma espécie de abordagem de varejo, diante do cenário de concessão pulverizada do direito, resultante de lides individuais, atitudes fundadas nessa linha de ação resultam em bons resultados.

\subsection{RESERVA DO POSSÍVEL}

Em busca de limites para o ativismo judicial, a reserva do possível costuma ser invocada como limitação ao Poder Judiciário (GRINOVER, 2011. p. 149). Contudo, na hipótese dos Poderes Executivo e Legislativo não promoverem as condutas necessárias para o rearranjo financeiro do Estado, a fim de que seus objetivos fundamentais possam ser 
alcançados, caberá ao Judiciário intervir nas respectivas políticas públicas (CANELA JUNIOR, p. 225-236). Sua intervenção, contudo, deve realizar-se de forma razoável e proporcional, buscando-se a garantia do mínimo existencial (GRINOVER, 2011. p. 149). Com efeito, ao apreciar determinada política pública, deve-se analisar todos os elementos que a envolvem, sob pena de invasão indevida na atividade política de governo, o que pode afetar na consecução de outras tarefas estatais (BUCCI, 2006. p. 23).

A reserva do possível não pode ser analisada subjetivamente por quem não visa cumpri-la. A depender das circunstâncias, pode ser necessário o cumprimento obrigatório de uma decisão, como no caso de providências imprescindíveis à efetivação de direitos fundamentais, tais as presentes em demandas pela dispensação de remédios e nas de que cuida este artigo, pela viabilização de vagas em creches e centros de educação infantil.

Isso significa condicionar o ativismo judicial à caracterização da omissão ou do descumprimento dos encargos políticos estruturantes do Estado brasileiro, de modo a comprometer a eficácia dos direitos sociais. Assim, a atuação do Poder Judiciário em situações de lesão aos direitos fundamentais ganha respaldo constitucional.

Assim, a partir da perspectiva neoconstitucionalista, autoriza-se o juiz, em cada caso sob seu apreço, a emprestar a máxima efetividade ao direito fundamental à educação infantil, valendo dos princípios da razoabilidade e proporcionalidade, adotando a melhor decisão, observando e materializando os direitos constitucionais pleiteados e a cláusula da reserva do possível orçamentário, a impor atenção às verbas públicas disponíveis para a execução de determinada política pública mas sem o engessamento argumentativo dessa restrição, rotineiramente invocado pelas edilidades.

\subsection{ENFRENTAMENTO DA JUDICIALIZAÇÃO DA EDUCAÇÃO INFANTIL A VAREJO}

É certo que a variável econômica ganha relevância em sede de ativismo judicial e efetividade de direitos. Contudo, apesar de encontrar-se vinculada às condições e possibilidades de execução de políticas públicas em prol da defesa e efetivação dos direitos sociais, não é imutável, devendo ser vista como condição a ser constituída previamente pelos atores políticos e sociais que são constitucionalmente responsáveis. (LEAL, 2009. p. 97).

Isso significa que ativismo judicial deve pautar-se segundo os interesses em discussão no caso concreto, adotando-se a decisão mais apta ao atingimento dos fins 
objetivados pela norma, respeitando-se as diretrizes da Constituição Federal e os atributos de cada um dos "poderes" constitucionalmente estabelecidos.

Em diversos momentos e formas percebem-se variáveis econômicas relacionadas ao problema do ativismo judicial nas prestações de dispensação de ensino infantil. Já se disse que a educação infantil, ao teor da Lei de Diretrizes e Bases da Educação Nacional, é atribuição dos municípios (artigo 11, inciso V, Lei 9.394/96) e será oferecida em creches, ou entidades equivalentes, para crianças de até três anos de idade e em pré-escolas, para as crianças de 4 (quatro) a 5 (cinco) anos de idade (artigo 30, Lei 9.394/96). Ordinariamente, essas crianças são alocadas em unidades integrantes da estrutura das redes públicas de ensino. Todavia, não raro, ocorre uma sub oferta de vagas na rede estatal e há necessidade de promover alocação de crianças na rede privada. Essa situação inspira pontos de contato entre o tema da judicialização do ensino infantil e a variável econômica. Trata-se, todavia, de um exame do tema a varejo.

Considere-se que o direito fundamental à educação infantil, como estatuído na lei, pressupõe vaga na escola mais próxima da residência da criança (artigo $4^{\circ}$, inciso X, Lei 9.394/96). A considerar essa premissa, preocupações residiriam na melhor forma de lidar com os reflexos da ingerência judiciária, por exemplo, regionalizando o município e credenciando entidades privadas para suprir a demanda decorrente de decisões judiciais, mediante contratação prévia sob preço controlado de vagas em todas as regiões ou nas que apresentem déficit.

Também seria conveniente investir em mecanismos pré-processuais de absorção dessas lides, ao modo de aferir se, de fato, há pretensão estatal resistida ou, pelo contrário, mera comodidade da parte do usuário do sistema de acesso à justiça. Esta última providência é também salutar porque reduz despesas públicas com a sucumbência processual, mormente porque, mesmo quando acionada a Defensoria Pública pela criança, representada pelos genitores ou tutores, sendo a entidade necessariamente mantida por distinto ente federado em relação ao município, não há impedimento a que seja beneficiária de honorários sucumbenciais, segundo se pode inferir do verbete 421 da Súmula do Superior Tribunal de Justiça: "Os honorários advocatícios não são devidos à Defensoria Pública quando ela atua contra a pessoa jurídica de direito público à qual pertença".

Em não havendo mecanismos de gestão do ativismo judicial temático, o ente municipal dispende maiores esforços com o controle posterior dos reflexos das decisões 
judiciais, importando dificuldade, inclusive de lidar com reflexos contábeis e de direito financeiro, além do controle externo, da parte dos Tribunais de Contas. Na ausência de gestão adequada, gastam-se mais recursos e gasta-se mal. Recursos financeiros e pessoas são demandados sem propósito finalístico com o ensino infantil, desvia-se o foco do principal para acessórios.

Desses apontamentos decorre a percepção de que a obtenção da educação infantil mediante a judicialização viabilizaria ao Judiciário beneficiar ou prejudicar setores em detrimento de outros, sob a legítima, embora equivocada preferência dos fins sociais às limitações econômicas do Estado. Diz-se equivocada a invocação por ausência de efetiva incompatibilidade entre uns e outras. A aplacar essas críticas, quanto mais controle houver nos mecanismos de implementação das decisões judiciais, mais eficientes serão e, quanto mais publicidade se fizer, melhor para a auditagem e a transparência dos processos relacionados, dos processos judiciais estrito senso e dos processos de trabalho direta e indiretamente relacionados à judicialização do ensino infantil.

\section{CONCLUSÃO}

O ativismo judicial e a eficácia social, jurídica e econômica de políticas públicas voltadas à educação infantil é a temática desenvolvida neste artigo, sob abordagem metodológica híbrida, que integrou pesquisa dogmática, e documental quantitativa, com fontes diretas e indiretas. Teorias constitucionais de viés pós-positivista e a Análise Econômica do Direito foram referenciais do desencadeamento proposto.

Demonstrou-se que o ativismo judicial em desenvolvimento no Brasil tem suporte na ordem jurídica e apontaram-se limites a sua encampação. Inúmeras críticas ao ativismo judicial foram enfrentadas, ora encampando, com propostas de melhoramento, ora rechaçando as posições contrárias. Contextualizadas as críticas ao movimento, constatou-se que, no específico caso da judicialização da educação infantil, o ativismo judicial acaba por integrar uma realidade econômica e social sequiosa pela materialização do direito fundamental das crianças às creches e pré-escolas, interagindo com as políticas públicas formais e as reprogramando, qualitativa e quantitativamente. Também se constatou haver relativa pouca judicialização coletiva e relativo pouco ativismo judicial coletivo no setor do ensino infantil.

Essa nova mecânica de funcionamento dos poderes estatais, que, segundo a crítica do ativismo judicial, viabilizaria ao Judiciário beneficiar ou prejudicar setores econômicos, 
setores da atuação estatal, setores do mercado que operam dentro e fora do Estado, em detrimento de outros, na realidade, em se tratando da temática estutada, atende a interesses econômicos do mercado no ambiente capitalista estatal.

A partir do ferramental da Análise Econômica do Direito, envolvendo o conceito de racionalidade limitada, a limitação informacional dos operadores de direito, e o princípio da eficiência em acepções jurídica e econômica, apreciou-se o custo social e econômico das demandas judiciais tendentes à operacionalização do direito fundamental destacado. Aspectos gerencias e de micro economia dessa cadeia de ajuizamentos foram apreciados e considerações exprimidas em vista da integração do ativismo no processo de realização das políticas de inclusão dos sujeitos do ensino infantil e da economicidade decorrente de melhor gestão do problema.

Por fim, a par do reconhecimento da relevância temática, revelou-se importante seguir com outros estudos qualitativos e quantitativos. Essas novas pesquisas são necessárias para possibilitar compreender o motivo da encampação e manutenção do ativismo judicial na execução do direito fundamental da criança à socialização e ao ensino em creches e préescolas de modo individual, mas não à igual ênfase no ativismo judicial coletivo e à formação de precedentes qualificados.

\section{REFERÊNCIAS}

ALEXY, Robert. Teoría de los derechos fundamentales. Trad. Ernesto Garzón Valdés. Madrid: Centro de Estudios Constitucionales, 1993.

ALVAREZ, Alejandro Bugallo. Análise econômica do direito: contribuições e desmistificações. Direito, Estado e Sociedade, Rio de Janeiro, v.9, n.29, p. 49-68, jul/dez, 2006. Disponível em: < https://revistades.jur.pucrio.br/index.php/revistades/article/view/287/260>. Acesso em: 01 Mar. 2020.

AMARAL FILHO, Jair do. A Endogeinização no desenvolvimento econômico regional no local. Revista Planejamento e Políticas Públicas, IPEA -INSTITUTO DE PESQUISA ECONÔMICA APLICADA, Rio de Janeiro, n. 23, 2001.

BARROSO, Luis Roberto. Judicialização, ativismo judicial e legitimidade democrática. 2008. Disponível em:

http://www.oab.org.br/editora/revista/users/revista/1235066670174218181901.pdf. Acesso em: 22 nov. 2015.

BOBBIO, Norberto. A era dos direitos. 11. ed. Rio de Janeiro: Campus,1992.

BONAVIDES, Paulo. Curso de direito constitucional. $12^{\mathrm{a}}$. ed. São Paulo: Editora Malheiros, 2002. 
BRASIL. Constituição Federal. Promulgada em 05 de outubro de 1988. Disponível em: http://www.planalto.gov.br/ccivil_03/constituicao/ConstituicaoCompilado.htm. Acesso em: 22 nov. 2015.

BRASIL. INSTITUTO NACIONAL DE ESTUDOS E PESQUISAS EDUCACIONAIS ANÍSIO TEIXEIRA (INEP). Censo da Educação Básica 2019: notas estatísticas. Brasília, 2020.

BUCCI, Maria Paula Dallari. Políticas públicas: reflexões sobre o conceito jurídico. São Paulo: Saraiva, 2006. p. 23

CANELA JUNIOR, Osvaldo. O orçamento e a 'reserva do possível': dimensionamento no controle judicial de políticas públicas. In: GRINOVER, Ada Pellegrini; WATANABE, Kazuo (Coords.). $\mathrm{O}$ controle jurisdicional de políticas públicas. Rio de Janeiro: Forense, 2011. p. 225-236. p. 233

CITTADINO, Gisele. Poder judiciário, ativismo judicial e democracia. Revista da Faculdade de Direito de Campos, Campos dos Goitacazes, ano II, n. 2 e ano III, n. 3, p. 135-144, 2001-2002. Disponível em https://core.ac.uk/download/pdf/16013577.pdf. Acesso em: 29 fev. 2020.

COOTER, Robert; ULEN, Thomas. Direito \& Economia. 5. ed. Porto Alegre: Bookman, 2010.

DECLARAÇÃO DOS DIREITOS DO HOMEM E DO CIDADÃO DE 1789. Disponível emhttp://pt.wikipedia.org/wiki/Declaracao_dos_Direitos_do_Homem_e_do_Cidadao. Acesso em: 21 nov. 2015.

DEMARCHI, Clóvis; VANDRESEN, Thaís. Do constitucionalismo ao neoconstitucionalismo: Aplicabilidade da teoria ao ordenamento constitucional brasileiro. Revista Direitos Culturais, Santo Ângelo, v. 9, n. 19, p. 46-62, mar. 2015. Disponível em: <http://srvapp2s.santoangelo.uri.br/seer/index.php/direitosculturais/article/view/1494>. Acesso em: 01 Mar. 2020.

FEREJOHN, John; PASQUINO, Pasquale. A teoria da escolha racional na ciência política: conceitos de racionalidade em teoria política. Rev. bras. Ci. Soc., São Paulo, v. 16, n. 45, fev. 2001. Disponível em http://www.scielo.br/. Acesso em 28 fev. 2020.

GOIÁS. Tribunal de Justiça. Súmula n 39: Tanto o mandado de segurança como a ação ordinária são instrumentos hábeis ao exercício do direito fundamental da criança ao atendimento em creche ou pré-escola situada nas proximidades da sua moradia, mantida ou custeada pelos municípios, admitindo-se bloqueio de valores em caso de descumprimento da obrigação (artigo 208, IV da CF e 54, IV do ECA). Aprovação: 19 set. 2016. Corte Especial do Tribunal de Justiça de Goiás. Publicação: DJe, n 2120, 28 set. 2016.

GRINOVER, Ada Pellegrini. O controle jurisdicional de políticas públicas. Rio de Janeiro: Forense, 2011. p. 149

LASSALE, Ferdinad. Que é uma constituição? Tradução de Walter Stönner. São Paulo, Edições e Publicações Brasil, 1933. Disponível em: < http://bibliotecadigital.puccampinas.edu.br/services/e-books/Ferdinand\%20Lassalle-1.pdf>. Acesso em: 01 Mar. 2020.

LEAL, Rogério Gesta. Condições e possibilidades eficácias dos direitos fundamentais sociais: o desafio do Poder Judiciário no Brasil. Porto Alegre: Livraria do Advogado, 2009. p. 97. 
MANKIW, N. Gregory. Princípios de microeconomia. 2014.

MORAES, Alexandre de. Direitos humanos fundamentais. 9a ed. São Paulo: Atlas, 2011.

PACHECO, Pedro Mercado. El Análisis Económico del Derecho - una reconstrucción teórica. Madrid: Cento de Estudios Constitucionales, 1994.

PARANÁ. Tribunal de Justiça. Súmula ${ }^{\circ}$ 53: Nas ações relativas a ensino público ou particular, que tenham como causa de pedir a irregularidade de atos comissivos, omissivos e cobrança, a competência é das Câmaras de Ensino, ainda que figure ente público na relação jurídico-processual. Aprovação: 25 abr. 2014. Publicação: DJe, n 1364, 2 jul. 2014.

PARETO, Vilfredo. Manual de Economia Política. Tradução de João Guilherme Vargas Neto. São Paulo, Nova Cultural, 1996.

PINHEIRO, Armando Castelar; SADDI, Jairo. Curso de Law \& Economic. Disponível em http://www.iadb.org. Acesso em: 29 jan. 2020.

POSNER, Richard A. Economic Analysis of Law. 7. ed. New York: Aspen Publishers, 2007.

RIO GRANDE DO NORTE. Tribunal de Justiça. Resolução N. ${ }^{\circ}$ 11: Aprova 41 (quarenta e um) novos enunciados de súmula da jurisprudência predominante do TJRN (Enunciados 05 a 45). Aprovação: 27 mar. 2019. Plenário do Tribunal de Justiça do Rio Grande do Norte. Publicação: DJe, n 11, 4 abr. 2019.

ROEMER. Introducción al Análises Económico del Derecho. 2000.

SÃO PAULO. Tribunal de Justiça. Súmula $n^{\circ}$ 63: É indeclinável a obrigação do Município de providenciar imediata vaga em unidade educacional a criança ou adolescente que resida em seu território. Publicação: DJe, n 933, 14 abr. 2011.

SÃO PAULO. Tribunal de Justiça. Súmula ${ }^{\circ}$ 64: O direito da criança ou do adolescente a vaga em unidade educacional é amparável por mandado de segurança. Publicação: DJe, $\mathrm{n}^{\circ}$ 933, 14 abr. 2011.

SÃO PAULO. Tribunal de Justiça. Súmula $\mathbf{n}^{\circ}$ 65: Não violam os princípios constitucionais da separação e independência dos poderes, da isonomia, da discricionariedade administrativa e da anualidade orçamentária as decisões judiciais que determinam às pessoas jurídicas da administração direta a disponibilização de vagas em unidades educacionais ou o fornecimento de medicamentos, insumos, suplementos e transporte a crianças ou adolescentes. Publicação: DJe, n 933,14 abr. 2011.

SARLET, Ingo Wolfgang. A eficácia dos direitos fundamentais. 3. ed. rev. e ampl. Porto Alegre: Livraria do Advogado, 2003.

SLONIAK, Marcos Aurélio. Acesso a justiça, direitos fundamentais e políticas públicas: uma análise do ativismo e garantismo processual. Disponível em: http://publicadireito.com.br/publicacao/ufpb/livro.php?gt=173. Acesso em: 22 nov. 2015.

TAPOROSKY, Barbara Cristina Hanauer; SILVEIRA, Adriana Aparecida Dragone. O Direito à Educação Infantil nos Tribunais de Justiça do Brasil. Educ. Real, Porto Alegre, v. 44, n. 1. Disponível em <http://www.scielo.br/scielo.php?script=sci_arttext\&pid=S217562362019000100607\&lng=en\&nrm=iso>. Acesso em 04 Abril 2020.

VARIAN, H. R. Microeconomia. Princípios Básicos: Eidtora Campos. 2003 
VASCONCELLOS, Marco Antonio Sandoval de; GARCIA, Manuel E. Fundamentos de economia. São Paulo: Saraiva, 2000.

VASQUEZ. Comentários sobre Algunos Supuestos Filosóficos del Analisis Economico Del Derecho. Isonomia n.5, 1996. 